Communications in Physics, Vol. 24, No. 2 (2014), pp. 146-154

\title{
A LOW COST MICROWAVE SYNTHESIS METHOD FOR PREPARATION OF GOLD NANOPARTICLES
}

\author{
NGO VO KE THANH \\ Faculty of Physics, University of Science, Vietnam National University, Ho Chi Minh City \\ and \\ Integrated Circuit Design Research \& Education Center, Vietnam National \\ University, Ho Chi Minh City \\ NGUYEN DANG GIANG \\ Integrated Circuit Design Research \& Education Center, \\ Vietnam National University, Ho Chi Minh City \\ LAM QUANG VINH \\ Faculty of Physics, University of Science, Vietnam National University, Ho Chi Minh City \\ HUYNH THANH DAT \\ Vietnam National University, Ho Chi Minh City
}

E-mail: ngovokethanh@yahoo.com or nvkthanh@vnuhcm.edu.vn

Received 17 March 2014

Accepted for publication 22 May 2014

\begin{abstract}
The gold nanoparticles (GNPs) in 15-20 nm size range have attracted attention for fabrication of smart sensing devices in biomedical sciences as diagnostic tools. Citrate capped GNPs are negatively charged, which can be exploited for electrostatic interactions with some positively charged biomolecules like antibody. In this study, we are developing a low-cost technique by using a common microwave system with medium power for synthesizing gold nanoparticles with using sodium citrate $\left(\mathrm{Na}_{3} \mathrm{Ct}\right)$ reduction in chloroauric acid $\left(\mathrm{HAuCl}_{4} \cdot 3 \mathrm{H}_{2} \mathrm{O}\right)$. It was found that the comparing with normal thermal method, the reaction by the microwave irradiation was much faster. Besides, effects of the sodium citrate concentration and optical properties of gold nanoparticle swere studied. The optical properties of gold nanoparticles suspension were characterized by using transmission electron microscopy (TEM), $X$-ray diffraction (XRD), and UV-VIS absorption spectroscopy (UV-Vis). Maximum absorbance wavelengths $\left(\lambda_{\max }\right)$ for gold nanoparticles are $\sim 518-524 \mathrm{~nm}$ with the size of 12-25 $\mathrm{nm}$. The size of gold nanoparticles decreases with increasing concentration of sodium citrate. Besides, the morphology of gold nanoparticles has spherical shape with face-centered-cubic ( $f c c$ ) crystalline structure.
\end{abstract}

Keywords: gold nanoparticles, particle size and distribution, microwave synthesis, nanostructures.

\section{INTRODUCTION}

The developing of simple methods for preparing the metal nanoparticles is expanding as an important branch in nanotechnology [1]. Recently, synthesis of gold nanoparticles (GNPs) has (C)2014 Vietnam Academy of Science and Technology 
attracted many scientists due to their novel electronic, optical, magnetic and thermal properties derived from the "quantum-sized effect" and their application in the areas of electronics, sensor and detector, medicine, chemistry, and biotechnology at the nanoscale [2-6].

For the last decade, many different methods for preparation of gold nanoparticles such as chemical [7, 8], electrochemical [9], photochemical [10], sonochemical [11], X-ray irradiation $[12,13]$, and laser ablation methods [14] were investigated. The famous strategy for synthesis of gold nanoparticles is to produce nanostructures of small and uniform size distribution because the special properties of gold nanoparticles depend on the size. Hence, the continuation of all these synthesis approaches showed the significance of this issue.

The Turkevich method [7] is the most common synthesis route of gold nanoparticles for its simplicity. The method is based on a reduction of choloroauric acid $\left(\mathrm{HAuCl}_{4} \cdot 4 \mathrm{H}_{2} \mathrm{O}\right)$ with sodium citrate $\left(\mathrm{Na}{ }_{3} \mathrm{Ct}\right)$ as reducing agent. In this method, $\mathrm{Na}_{3} \mathrm{Ct}$ is added into heating solution of $\mathrm{HAuCl}_{4}$ on a hot-plate heating and then colloidal gold nanoparticles are formed after ten minutes. However, a problem in this method is that conductive heating with using a hot-plate heating is not efficient to achieve fast and uniform heat tranfer to the reactants. Hence, the size and shape of gold nanoparticles in this method are affected with un-uniform size distribution.

Microwave heating with the high efficiency in energy transfer leads to rapid volumetric heating, simple, capable of improving the reaction rates and uniformity of products as a solution for these problems. Besides, some advantages for microwave synthesis include the increase of collision possibility between molecules and the decrease in the activation energy [15]. The result is that the reactants could enhance reactions. Therefore, it is showed that the synthesis of gold nanoparticles by microwave heating has the advantage over conventional methods [16].

In our work, gold nanoparticles were synthesized in a closed chamber of common microwave system which is modified by our group to developing cheaper tools for preparation of metal particles in nanotechnology. The products prepared by the microwave and the conventional heating methods were compared. Effects of sodium citrate concentration on gold particles size were also discussed. Further, structural property, morphology and absorption spectrocopy of the gold nanoparticles are shown.

\section{EXPERIMENTAL METHODS}

\section{Materials}

All chemical materials were G.R grade. Sodium citrate $\left(\mathrm{Na}_{3} \mathrm{Ct}\right)$ andchloroauric acid $\left(\mathrm{HAuCl}_{4} .3 \mathrm{H}_{2} \mathrm{O}\right)$ were purchased from Merk andSigma-Aldrichcompany. De-ionic water was used throughout experiments.

\section{Instruments}

The preparation of gold nanoparticles was carried out by a microwave system (Electrolux, EMM1908W, Max power: $700 \mathrm{~W}$ ) as shown in Fig. 1. The UV-Vis absorption behaviors for gold nanoparticles were recorded by using UV/vis spectrophotometer (Dynamca- HALO RB-10). Transmission electron microscopy (JEOL JEM--1400) and X-ray diffraction (XRD) by using a Brucker D5005 diffractometer were employed to characterize and analyze the shape and size of the gold nanoparticles. 


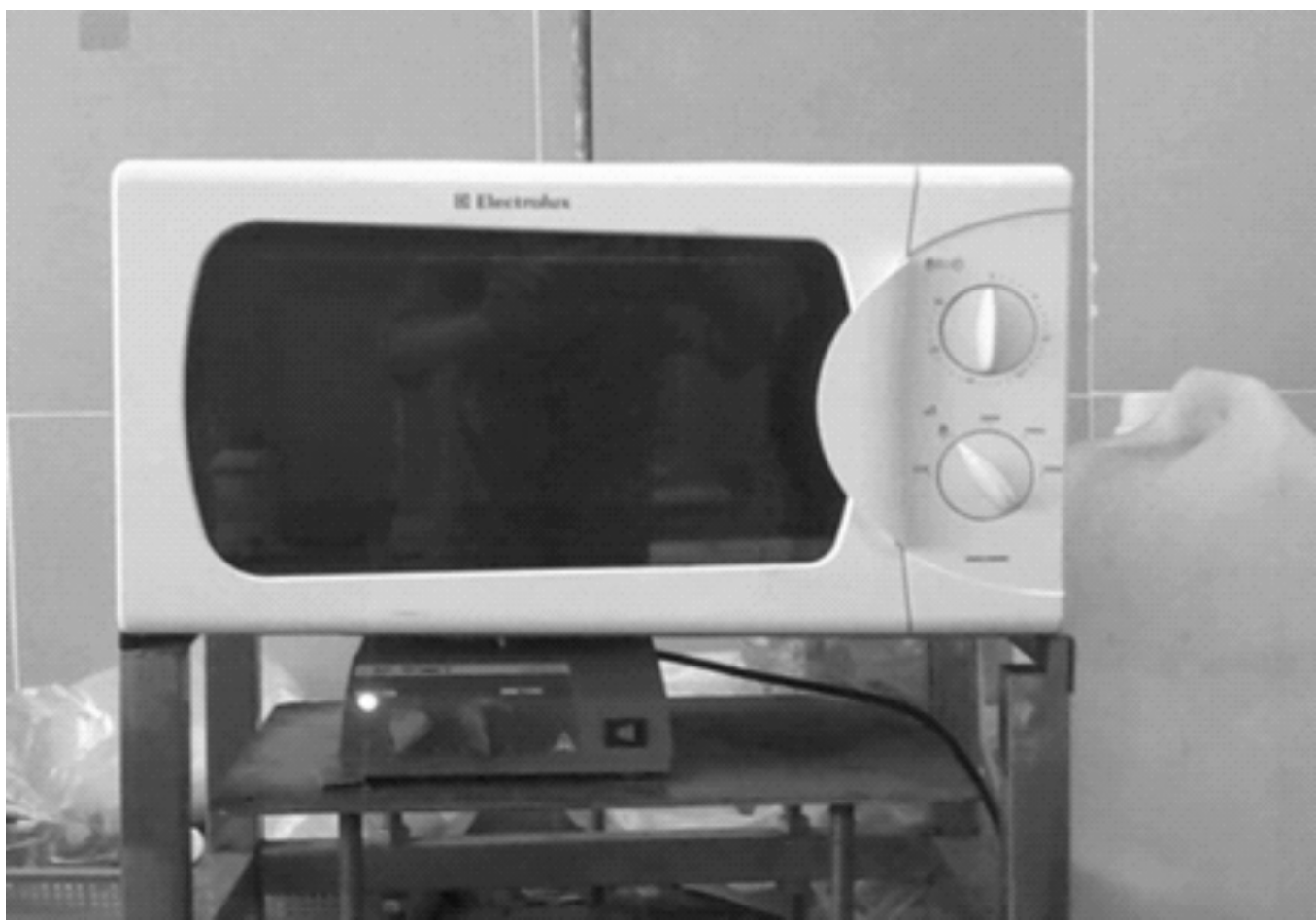

Fig. 1. Model for microwave heating equipment for preparing gold nanoparticles

\section{Synthesis of gold nanoparticles by microwave and thermal heating methods}

For preparation of gold nanoparticles by using microwave and conventional heating techniques, the concentration of chloroauric acid and sodium citrate solution, reaction time and temperature for synthesis gold nanoparticles are shown in Table 1 . The model for microwave heating equipment is shown in Fig. 1. For microwave heating, $1 \mathrm{ml}$ chloroauric acid solution and $1 \mathrm{ml}$ sodium citrate solution were dissolved in $18 \mathrm{ml} \mathrm{H}_{2} \mathrm{O}$ and the solution was placed into the microwave oven chamber (EMM1908W, Electrolux Co) to react for 10 min at $210 \mathrm{~W}$. Besides, $1 \mathrm{ml}$ chloroauric acid, $1 \mathrm{ml}$ sodium citrate solution and $18 \mathrm{ml} \mathrm{H}_{2} \mathrm{O}$ were put into $100 \mathrm{ml}$ vial equipped with a magnetic stirring bar. Then the vial was put into a $100^{\circ} \mathrm{C}$ hot-plate (Model: HJ-3, China) to react for $20 \mathrm{~min}$. The temperature of the solution was controlled by using thermometer.

\section{RESULTS AND DISCUSSION}

Fig. 2 shows UV-Vis curves of gold nanoparticles produced by microwave and thermal heating, where the concentration of chloroauric acid and sodium citrate, and the reaction time were the same. It can be seen that absorbance of gold nanoparticles colloid produced by microwave heating was higher than that of thermal heating. The Beer-Lambert law shows that a UV-vis absorbance is directly proportional to the path length and concentration of the suspension. Hence, we can indicate that suspension produced by microwave heating has a higher concentration of gold nanoparticles. 


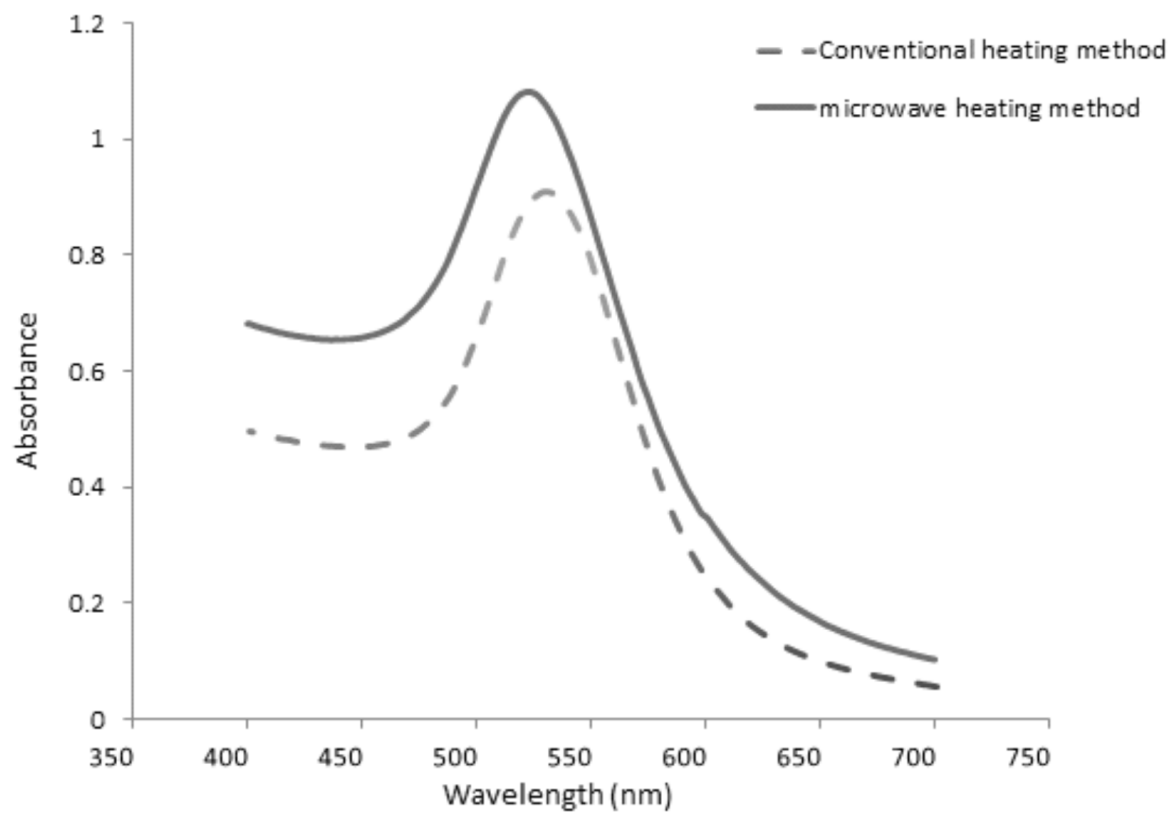

Fig. 2. A comparision of the UV-vis absorption of gold nanoparticles produced by microwave and thermal heating at the same the concentration of chloroauric acid and sodium citrate

Table 1. Experimetal conditions for preparation of gold nanoparticles by microwave radiation and conventional thermal heating

\begin{tabular}{|c|c|c|c|c|c|c|}
\hline \multicolumn{7}{|c|}{ Conventional heating method } \\
\hline $\mathrm{No}$ & $\begin{array}{c}\mathrm{H}_{2} \mathrm{O} \\
(\mathrm{ml})\end{array}$ & $\begin{array}{c}\text { Concentration of } \\
\mathrm{HAuCl} / \mathrm{Na}_{3} \mathrm{Ct} \\
(\mathrm{mM})\end{array}$ & $\begin{array}{c}\text { Reaction } \\
\text { time } \\
(\text { minute })\end{array}$ & $\begin{array}{c}\text { Reaction } \\
\text { temperature }\left({ }^{\circ} \mathrm{C}\right) \\
\text { or Power }(\mathrm{W})\end{array}$ & $\begin{array}{c}\text { Average } \\
\text { diameter } \\
(\mathrm{nm})\end{array}$ & $\begin{array}{c}\text { Standard } \\
\text { deviation } \\
(\mathrm{nm})\end{array}$ \\
\hline 1 & 18 & $5 / 20$ & 20 & 100 & $18 \pm 4$ & 3.80 \\
\hline \multicolumn{7}{|c|}{ Microwave heating method } \\
\hline 1 & 18 & $5 / 10$ & 10 & 210 & $24 \pm 5$ & 4.48 \\
\hline 2 & 18 & $5 / 15$ & 10 & 210 & $15 \pm 3$ & 2.54 \\
\hline 3 & 18 & $5 / 20$ & 10 & 210 & $15 \pm 2$ & 2.18 \\
\hline 4 & 18 & $5 / 25$ & 10 & 210 & $14 \pm 3$ & 2.47 \\
\hline
\end{tabular}

The results of particle size analysis for gold nanoparticles prepared by both microwave and thermal heating methods as shown in Table 1. The average diameter and standard deviation of gold nanoparticles produced by microwave heating at the concentration of chloroauric acid ( 5 $\mathrm{mM}$ ) and sodium citrate (20 mM) were estimated from particle pictures taken in the TEM (Fig. $3 \mathrm{~b}$ ). Besides, Fig. 3a shows the TEM image of gold nanoparticles which were prepared at ratio 5:20 for concentration of $\mathrm{HAuCl}_{4} / \mathrm{Na}_{3} \mathrm{Ct}$ and $100^{\circ} \mathrm{C}$ for $20 \mathrm{~min}$ by thermal heating. It can be seen 
that gold nanoparticles produced by microwave heating have a narrow size distribution because the heating by microwave radiation is more uniform. It is found that keeping uniform temperature distribution was an important factor in narrow distribution of nanoparticles reported by Fuelong $e t$ al. [17]. Besides, it has been known that microwave radiation can penetrate the reaction solution with different wavelength to heating the whole solution quickly and uniformly. On the other hand, but in the conventional thermal heating by a hot plate exists there a temperature gradient due to the heat conduction. Therefore, it can conclude that the microwave heating is more suitable for synthesis of narrowly dispersed gold nanoparticles.

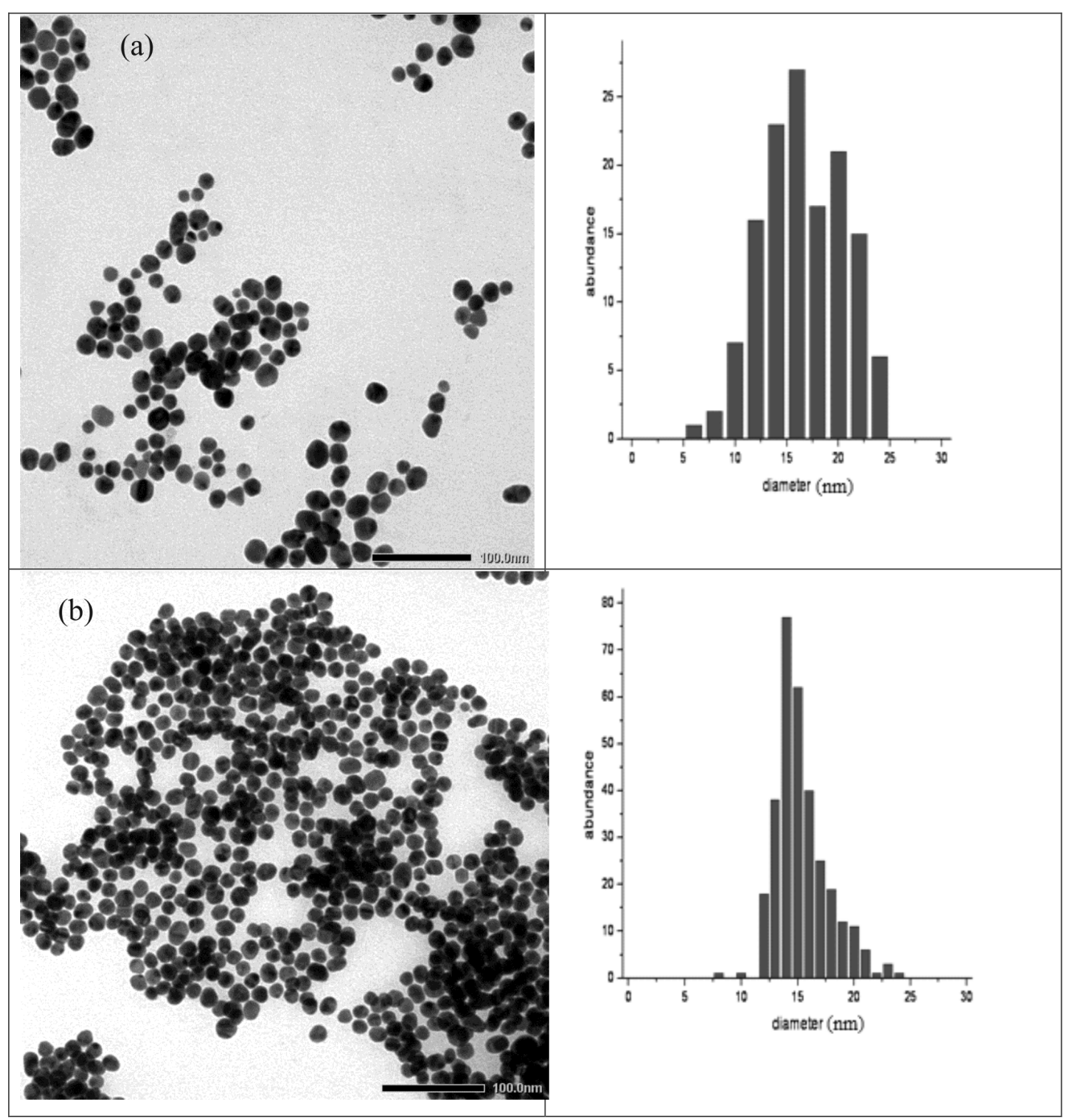

Fig. 3. TEM images of gold nanoparticles produced by thermal (a) and microwave (b) heating at the same the concentration of chloroauric acid $(5 \mathrm{mM})$ and sodium citrate $(20 \mathrm{mM})$ 


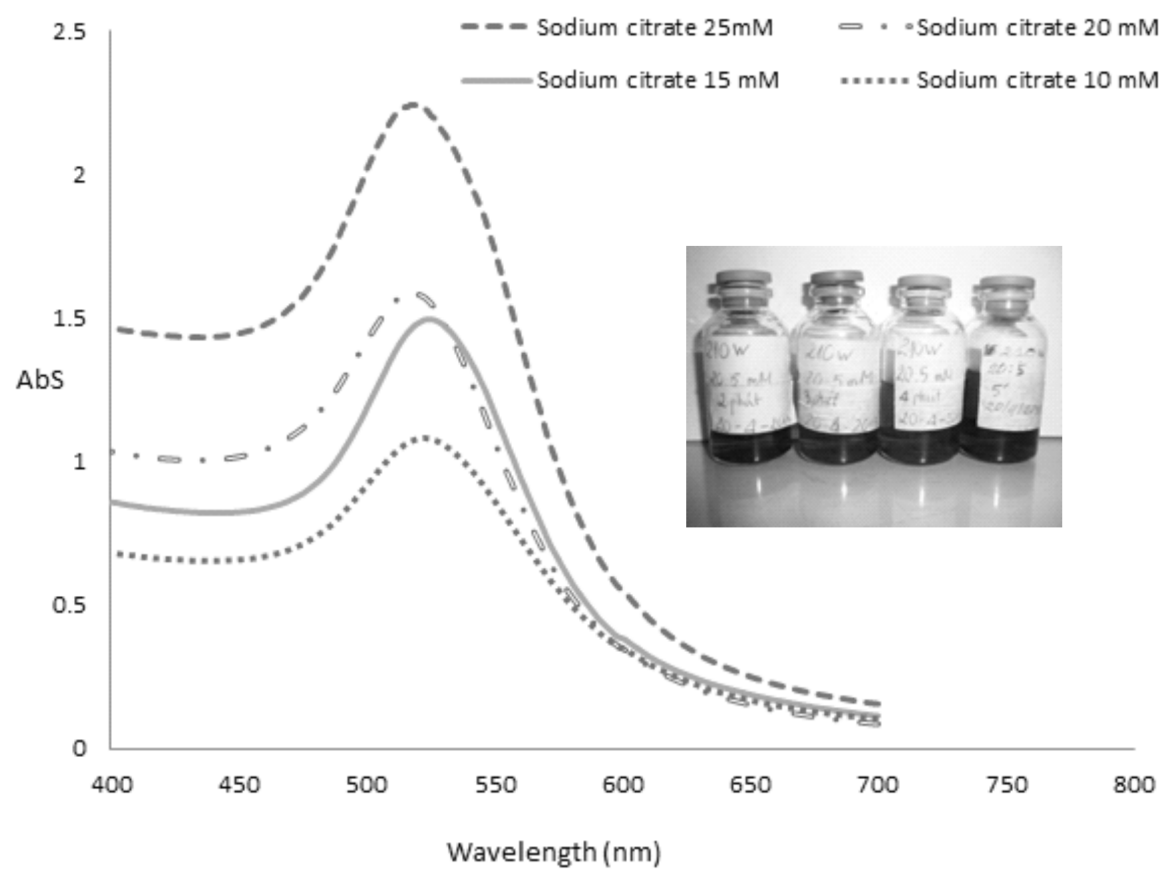

Fig. 4. The UV-visible curves of gold nanoparticles produced under different concentrations of sodium citrate by microwave heating for $10 \mathrm{~min}$ at $210 \mathrm{~W}$. The concentration of chloroauric acid was the same $(5 \mathrm{mM})$

Fig. 4 shows the UV-Vis spectrocopy of gold nanoparticles produced with different concentration of sodium citrate by microwave heating methods. From figure, the results of maximum absorbance wavelength $\left(\lambda_{\max }\right)$ for gold nanoparticles are $\sim 518-524 \mathrm{~nm}$ with size 12-25 nm as shown in Fig. 5. Similar result was also observed by Seung Kown Seol et al. using by the reduction of chloroauric acid $\left(\mathrm{HAuCl}_{4}\right)$ reacted with sodium citrate $\left(\mathrm{Na}_{3} \mathrm{Ct}\right)$ in de-ionized water with high microwave power [18]. It has long been known that with the increase of the concentration of sodium citrate in mirowave radiation method, maximum absorbance wavelength $\left(\lambda_{\max }\right)$ and the average diameter of gold nanoparticles decrease and the size distribution becomes narrower.

Otherwise, the morphology of gold nanoparticles prepared by microwave heating with a different sodium citrate concentration was further investigated by TEM. Fig. 5 shows TEM brightfield images of the gold nanoparticle samples. It is obvious that the morphology and size of the samples were affected by sodium citrate concentration. The sample at $10 \mathrm{mMNa}_{3} \mathrm{Ct}$ contains a spherical and polygon shape with diameter $\sim 15-30 \mathrm{~nm}$. On the contrary, the samples at 20, 25 $\mathrm{mM} \mathrm{Na}{ }_{3} \mathrm{Ct}$ consist of spherical shape with small particles size $\sim 12-15 \mathrm{~nm}$. From the above $\mathrm{UV}$-vis measurements and TEM, we can suggest that $\mathrm{Na}_{3} \mathrm{Ct}$ concentrational parameter is a critical factor in determining the final size and morphology of the synthesized gold nanoparticles by using microwave heating reported by Nguyen Ngoc Long and Le Van Vu et al. [19]. 


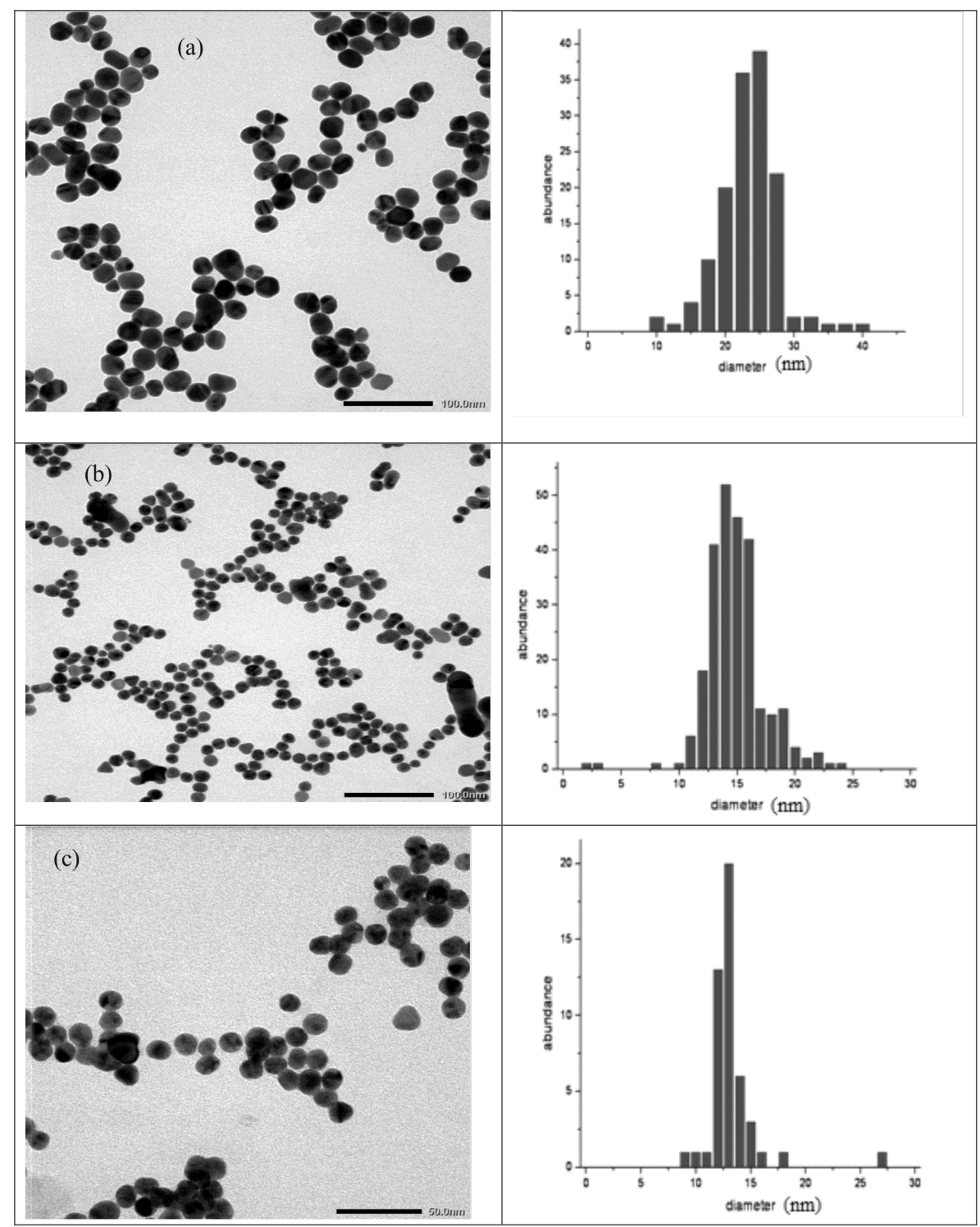

Fig. 5. TEM micrographs for gold nanoparticles under different concentration of sodium citrate by microwave heating for $10 \mathrm{~min}$ at $210 \mathrm{~W}$. (a) $10 \mathrm{mM}$, (b) $15 \mathrm{mM}$, (c) $25 \mathrm{mM}$ sodium citrate

Besides, X-ray diffraction (XRD) analysis was employed to identify the crystallinity of the as-synthesized GNPs. As for example, a typical XRD pattern for the sample synthesized at 5:20 mM $\left(\mathrm{HAuCl}_{4}: \mathrm{Na}_{3} \mathrm{Ct}\right)$ is presented in Fig. 6. The recorded XRD pattern exhibits peaks at $38.19^{\circ}, 44.37^{\circ}, 64.59^{\circ}, 77.58^{\circ}$ in the $2 \theta$ range of $20-80^{\circ}$ which are assignable to (111), (200), (220), and (311) planes of gold with face-centered-cubic (fcc) crystalline structure, as illustrated 
by TEM picture in Fig.3b. Secondly, the lattice constant determined from XRD pattern is $a=$ $4.077 \AA, a=4.693 \AA, a=4.079 \AA, a=4.078 \AA$ in good agreement with the standard diffraction pattern of cubic gold metal (Pattern 4-784). Similar trend was also observed by Nguyen Ngoc Long and Le $\mathrm{Van} \mathrm{Vu}$ et al. in their research when they synthesized gold nanopaticles using by photochemical approach using X-ray irradiation with sodium citrate and chloroauric acid solution [19].

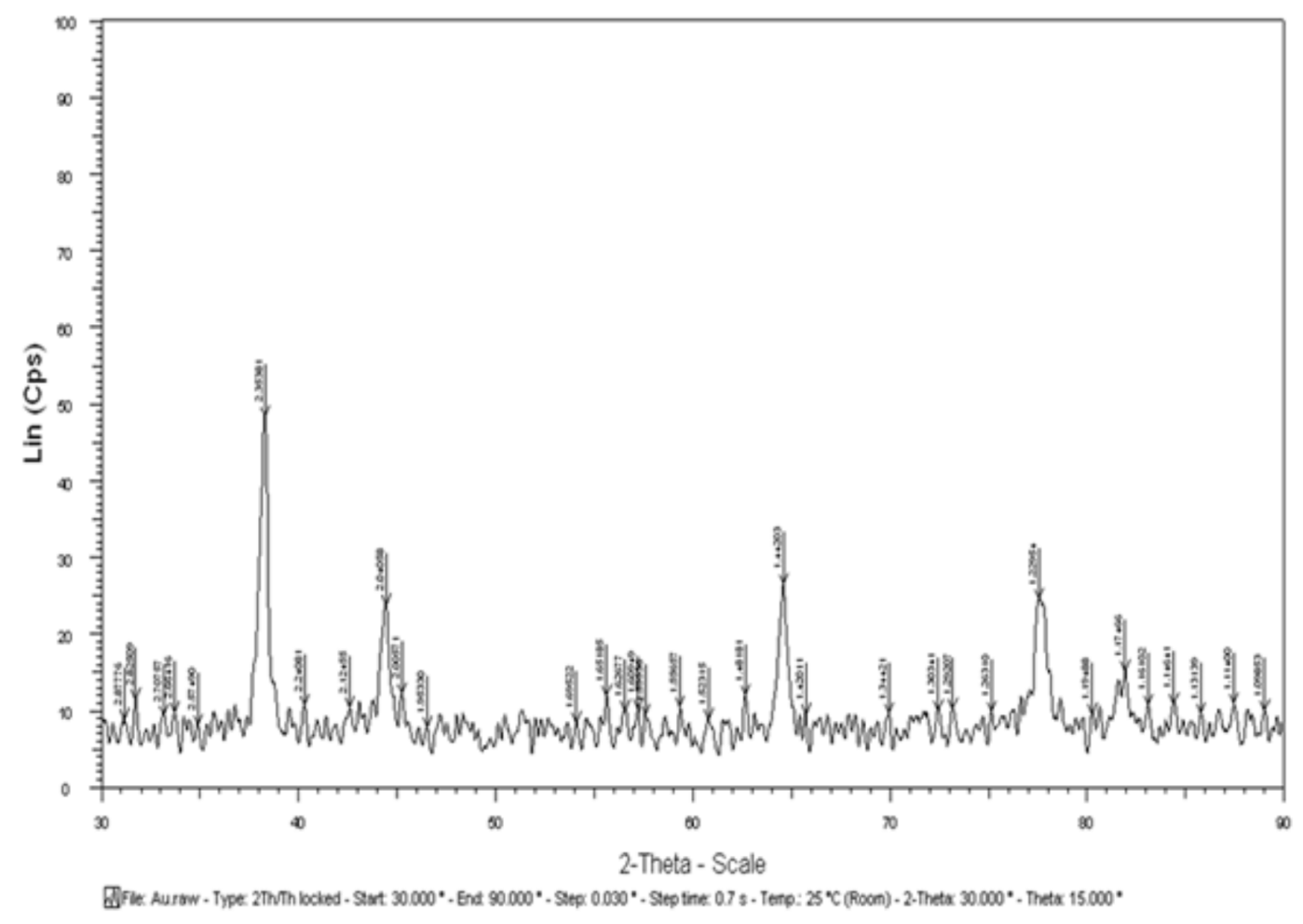

Fig. 6. The XRD curves of gold nanoparticles produced by microwave heating for $10 \mathrm{~min}$ at $210 \mathrm{~W}$. The concentration of chloroauric acid: Sodium citratewas 5:20 mM

\section{CONCLUSION}

In this paper, the colloid of gold nanoparticles has been prepared by a low cost microwave technique where microwave radiation was used as a heating source. Compared to a thermal heating method, mirowave radiation gave a much faster reaction and provided a higher concentration and a narrow size distribution of gold nanoparticles with the same concentration of chloroauric acid and sodium citrate solution. Other conditions, such as concentration of sodium citrate $\left(\mathrm{Na}_{3} \mathrm{Ct}\right)$ have the effects on the size and distribution of gold nanoparticles. The as-prepared gold nanoparticles were characterized by UV-vis spectroscopy, XRD and TEM. It can be found that the size of the particles decreases with increasing the concentration of sodium citrate $\left(\mathrm{Na}_{3} \mathrm{Ct}\right)$. Besides, the morphology of gold nanoparticles has a spherical shape with face-centered-cubic (fcc) crystalline structure. 


\section{ACKNOWLEDGEMENTS}

The authors would like to thank Prof. Dr. Dang Luong Mo, Vietnam National University for valuable discussion and the Laboratory of Nano Chemisty, the Department of Chemistry, the University of Science Ho Chi Minh City for providing microwave system. This work is partially supported by Department of Science and Technology of Ho Chi Minh City.

\section{REFERENCES}

[1] P. Raveendran, J. Fu, and S. L. Wallen, Green Chemistry 8 (1) (2006) 34-38

[2] R. Sardar, A. M. Funston, P. Mulvaney, R. W. Murray, Langmuir. 25 (2009) 13840

[3] R. A.Sperling, P. R. Gil, F. Zhang, M. Zanella, and W. J. Parak, Chem. Soc. Rev. 37 (2008) 1896

[4] E. Boisselier and D. Astruc, Chem. Soc. Rev. 38 (2009) 1759

[5] G. C. Schatz, A. A. Lazarides, K. L. Kelly, and T. R. Jensen, J. Mol. Struc. (Theo. Chem.) 59 (2000) 529

[6] J. S. Lee, Gold Bull. 43 (3) (2010) 189-199

[7] J. Turkevich, P. C. Stevenson, and J. Hillier, Discuss. Faraday. Soc. 11 (1951) 55-75

[8] M.C. Daniel and D. Astuc. Chem. Rev. 104 (2004) D293-D346

[9] C. J. Huang, P. H Chiu, Y. H. Wang, W. R. Chen, and T. H. Meen, Journal of the Electrochemical Society 153 (12) (2006) D193-D198

[10] S. Kundu, S. Panigrahi, S. Praharaj, S. Basu, S. K. Ghosh, A. Pal, and T. Pal, Nanotechnology. 18 (7) (2007) 075712-075719

[11] V. G. Pol, A. Gedanken, and J. Calderro-Moreno, Chem. Mater. 15 (2003) 1111-1118

[12] C. C. Kim, C. H. Wang, Y. C. Yang, Y. Hwu, S. K. Seol, Y. B. Kwon, C.H. Chen, H. W. Liou, H. M. Lin, G. Margaritondo, and J. H. Je. Materials Chemistry and Physics 100 (2006) 292-295.

[13] C. H. Wang, C. J. Liu, C. L. Wang, T. E. Hua, J. M. Obliosca, K. H. Lee, Y. Hwu, C. S. Yang, R. S. Liu, H. M. Lin, J. H. Je, G. Margaritondo. J. Phys. D: Appl. Phys. 41 (2008) 195301

[14] R. Sreeja, P. M. Aneesh, A. Aravind, R. Reshmi, R. Philip, and M. K. Jayaraj. J. Electrochem. Soc. 156 (10) (2009) K167-K172

[15] H. M. Kingston and S. J. Haswell, American Chemical Society, Washington, DC, (2005)

[16] S. Komarneni, D. Li, B. Newalkar, H. Katsuki, and A.S. Bhalla, Langmuir. 18 (2002) 5959-5962

[17] D. N. Fuelong, A. Launikonis, and W. H. F. Sasse, J. Chem. Soc., Faraday Trans. 80 (3) (1984) 571-588

[18] S. K.Seola, D. Kima, S. Junga, and Y. Hwu, Materials Chemistry and Physics 131 (2011) 331-335

[19] N. N. Long, L. V. Vu, C. D. Kiem, S. C. Danh, C. T .Nguyet, P. T. Hang, N. D. Thien, and L. M Quynh, Journal of Physics: Conference Series 187 (2009) 012026 